\title{
Vaginal Tubulosquamous Polyp
}

National Cancer Institute

\section{Source}

National Cancer Institute. Vaginal Tubulosquamous Polyp. NCI Thesaurus. Code

C128061.

A rare benign lesion that arises from the vagina. It is characterized by the presence of squamous epithelial and tubular structures in a fibrovascular stroma. 